\title{
Modeling of 3D technological fields and research of principal perspectives and limits in productivity improvement of selective laser melting
}

\author{
Vladimir D. Gurin ${ }^{\mathrm{a}}$, Dmitry V. Kotoban, Pavel A. Podrabinnik, Ivan V. Zhirnov, \\ Pavel Yu. Peretyagin and Anna A. OKunkova \\ Moscow State University of Technology "STANKIN", 1 Vadkovsky per., Moscow GSP-4, 127994, Russian Federation
}

Received 3 October 2016, Accepted 8 December 2016

\begin{abstract}
Nowadays the technological perspectives of selective laser melting are limited by available equipment on the market. Most of the manufactures produce SLM-machine with the maximum power of laser system $200 \mathrm{~W}$, this makes processing very slow and it significantly reduces the field of potential applications for the technology. Meanwhile the limits of laser power are linked to a problem of its effective use. In the current work, the future perspectives of technology are investigated by modeling of 3D technological fields.
\end{abstract}

Key words: Selective laser melting / technological fields / perspectives / modeling / technological limits

\section{Introduction}

Nowadays selective laser melting is one of the most perspective technology of metallic parts' production. It was developing very active for the last twenty years and today it steps from production of plastic models to production of functional 3D-objects with guarantied properties close to the required level of casting metals. The technology includes the steps of pre- and post-production, when the main process consists of layer-by-layer growing of solid 3D-object. A laser beam melts the each layer; a program, which was generated automatically by a control system of SLM-machine, controls the laser beam movement. The main advantages of the technology are an absence of mechanical treatment and relative simplicity of approach (absences of plural operating and machining steps, which only enlarge the quantity of problems related to efficient referencing of a part on a worktable or on a pallet of the machine for implementation of each step of the production).

Modern additive manufacturing has a huge economical annual growth and progress. By data of famous industry analyst Terry Wohlers [1], the US corporation Boeing produced already more than 20 thousand products by method of selective laser melting. Moreover about 30 different metallic components are already used in production of each Boeing 787 Dreamliner. The European

${ }^{a}$ Corresponding author: lecast@stankin.ru corporation Airbus S.A.S. produces the 50-70\% weightlighted brackets by SLM. Another good example of the parts' production for the purposes of machinery industry is company ACTech GmbH (Germany), which is specialized on production of final functional products by additive manufacturing methods from metallic and plastic powder materials. More than a half of orders is individual or small-serial production. More than $75 \%$ of products are consumed by automotive industry; aviation sector, heavy engineering and energetic industry consume the rest by equal proportions (around 5-7\%). Three fourth of the products are aimed to satisfy needs of the European market [2].

The last scientific publications [3-7], which are related to the current topic, aimed to search the solution for the known disadvantages of SLM technology. One of the most important disadvantages is production time. The technology is strong limited by the efficiency of laser beam power use. Practice showed that direct increase of laser beam power gives an opposite effect, makes processing simply impossible. Most of material evaporates, active material granules emission occurs, material enters into active interaction with the environment on physical and chemical levels.

The current research aim of the study is pointed to a problem of reduction of the influence of the described negative effects on the quality of the final 3D-object obtained by SLM and to search of possible improvement of processing efficiency. The research is based on obtained 


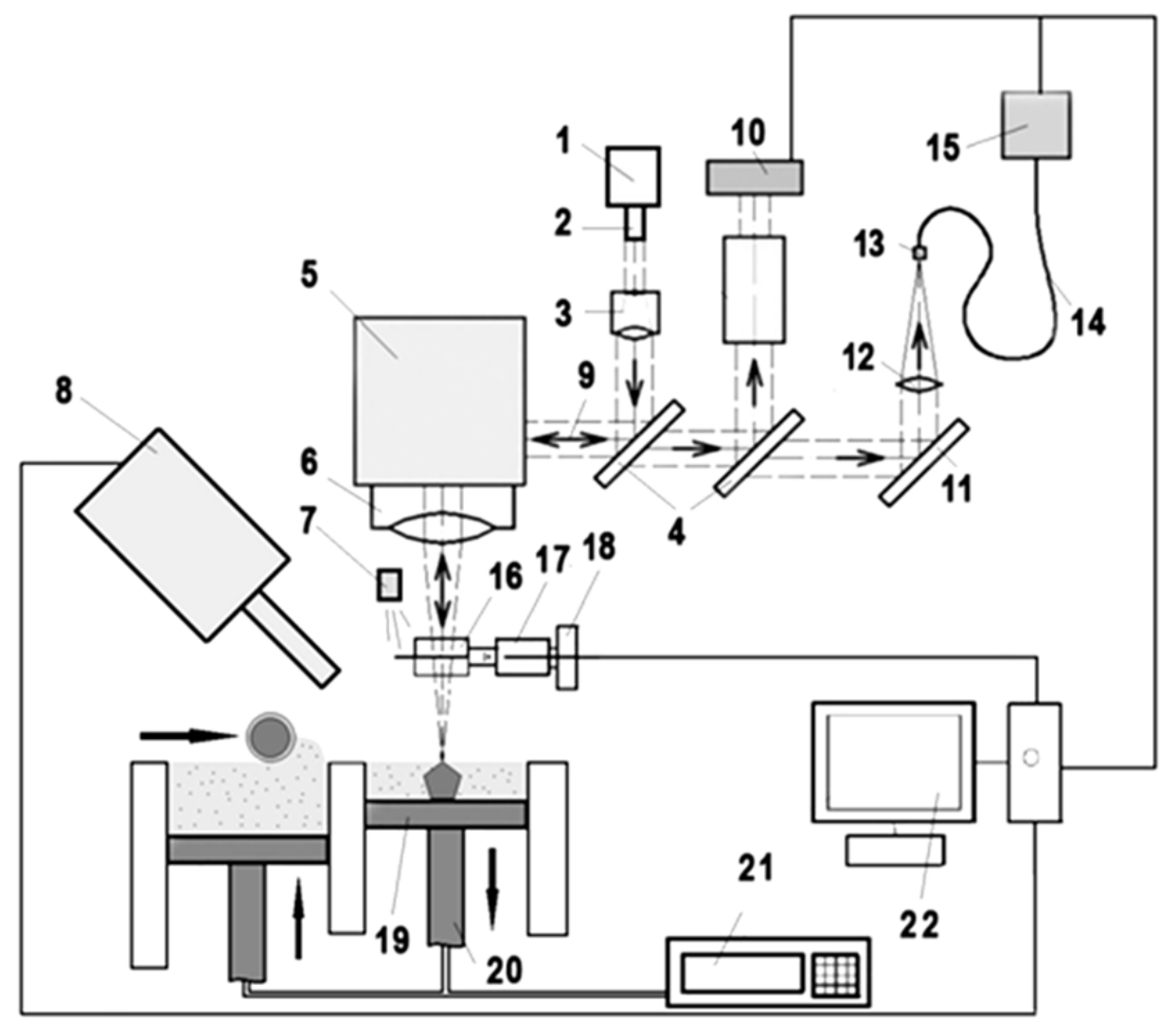

Fig. 1. Experimental setup: (1) laser beam source, (2) collimator, (3) pi-Shaper, (4) mirror, (5) scanator, (6) F-theta lens, (7) laser illumination, (8) high speed CCD camera, (9) laser beam travel path, (10) short range IR-camera, (11) mirror, (12) pyrometer lens, (13) signal receiver, (14) optic fiber, (15) pyrometer, (16) BCube optic mirror, (17) attenuator, (18) LaserCam-HRTM CCD camera, (19) working platform, (20) moving piston, (21) electronic micrometer, (22) computer.

experimental data and includes modeling of 3D technological fields in area out of the technological limits of the equipment.

\section{Experimental setup}

The experimental setup is presented on the Figure 1. The main principles of construction of the experimental stand are performed in accordance to typical construction of the SLM-machine [7-9]. The setup was supplied by an optical diagnostic system and by a system of laser beam modulation. All experiments have been performed using the developed optical diagnostic system.

Cobalt-chromium alloy (Tab. 1) has been chosen for the experiments as a powder material according to his excellent heat resistivity and neutral reaction to the absence of protective atmosphere. The granuloformometric characteristics of the powder were controlled by an OCCHIO 500 NANO optical granuloformometer (a resolution of the camera with $6,6 \mathrm{mln}$. pixels; lens type is telecentric buzzer; lens resolution is $0,38 \div 4,7$ micron/pixel) (Figs. 2, 3). Powder material layer nominal thickness in this study has been $30 \div 40 \mu \mathrm{m}$ and controlled by an optical microscope.
During the experiments, two main SLM factors were varied as laser beam power $\mathrm{P}$ and laser beam scanning speed V. Laser power P was varied from 10 to $200 \mathrm{~W}$, scanning speed was varied from 5 to $100 \mathrm{~mm} / \mathrm{s}$. Plenty of the authors obtained these main factors and their influences on the SLM-formation of single tracks [10-13]. The third varied factor was laser beam power density distribution. On the experimental setup three different laser beam power distribution was obtained (Gaussian, Flat-top and Inverse Gaussian) [7-9]. For the last 25 years plenty of the authors firstly proved the mathematical possibility of other laser beam power density distributions [14-17]; next they developed the optical principles and obtained them in their experiments, searched their possible application in the context of technology and machinery [18-24].

For each combination of the factors (laser beam power, scanning speed and laser beam mode), the ten-layer-3Dobjects were produced. The length of the objects was $10 \mathrm{~mm}$, each layer consists of 10 laser beam paths. The strategy, which was used to obtain the objects, was double hatching, one of the most wide-spread for object production in the conditions of real manufacturing.

The temperature in the molten pool was controlled by a multiwave pyrometer MPL4-900/2500: a range of measured temperatures is $1000 \div 2500{ }^{\circ} \mathrm{C}$, a range of 
V.D. Gurin et al.: Mechanics \& Industry 17, 714 (2016)

Table 1. Chemical composition of CoCrMo powder.

\begin{tabular}{ccccccccc}
\hline Element & $\mathrm{Co}$ & $\mathrm{Cr}$ & $\mathrm{Mo}$ & $\mathrm{Si}$ & $\mathrm{Mn}$ & $\mathrm{Fe}$ & $\mathrm{C}$ & $\mathrm{Ni}$ \\
\hline Content, $\%$ & $60-65$ & $26-30$ & $5-7$ & $>1$ & $>1$ & $>0,75$ & $>0,16$ & $>0,1$ \\
\hline
\end{tabular}

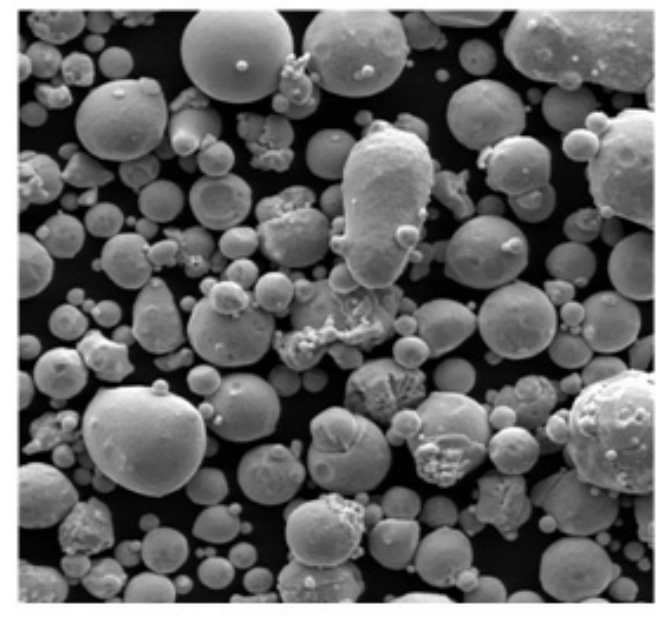

(a)

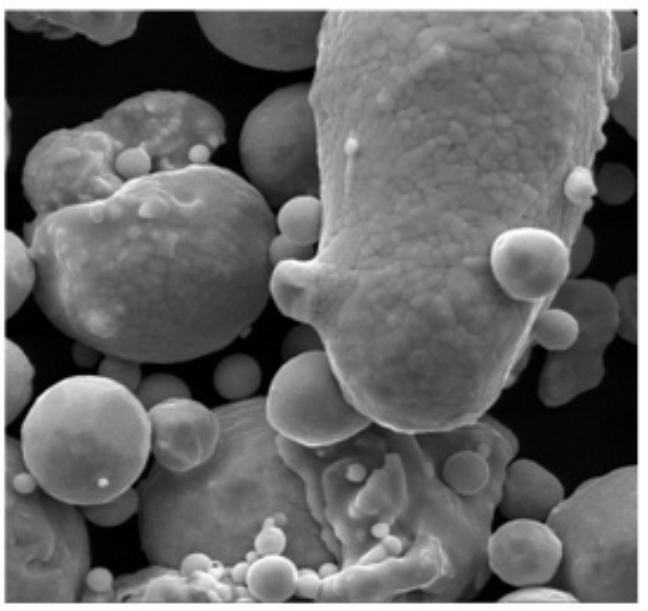

(b)

Fig. 2. SEM images of CoCrMo powder $\times 1200$ (a) and $\times 4000$ (b).

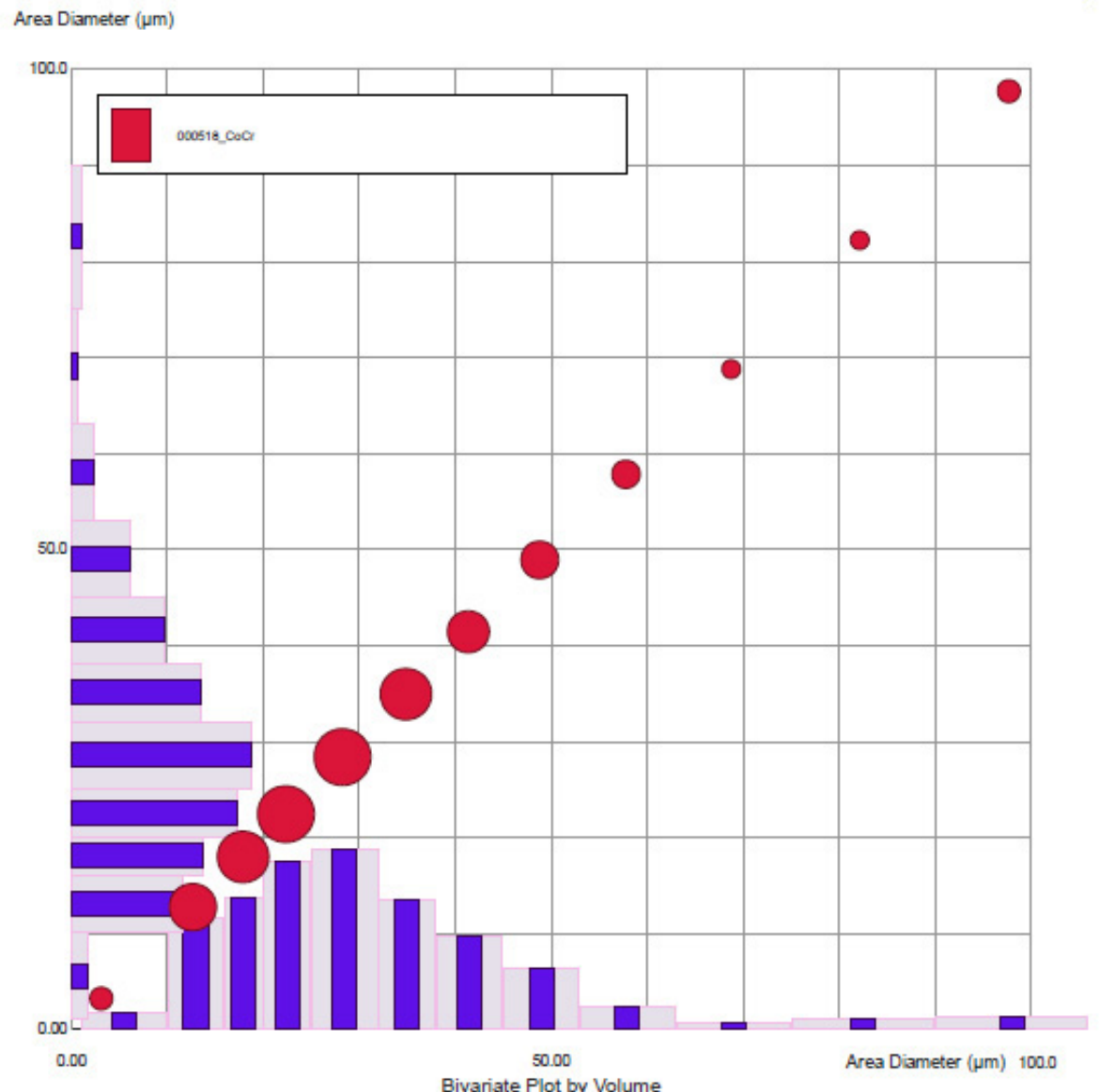

Fig. 3. Granulometric analysis of CoCrMo powder. 
V.D. Gurin et al.: Mechanics \& Industry 17, 714 (2016)

Table 2. Average temperatures on the surface of molten pool measured by pyrometer in accordance with SLM-processing factors.

\begin{tabular}{ccccccccc}
\hline \multicolumn{7}{c}{ Laser beam power density distribution (Mode) } \\
\hline & Gaussian & \multicolumn{5}{c}{ Inverse Gaussian } \\
\hline $\mathrm{P}, \mathrm{W}$ & $\mathrm{V}, \mathrm{mm} / \mathrm{s}$ & $T_{\mathrm{av}},{ }^{\circ} \mathrm{C}$ & $\mathrm{P}, \mathrm{W}$ & $\mathrm{V}, \mathrm{mm} / \mathrm{s}$ & $T_{\mathrm{av}},{ }^{\circ} \mathrm{C}$ & $\mathrm{P}, \mathrm{W}$ & $\mathrm{V}, \mathrm{mm} / \mathrm{s}$ & $T_{\mathrm{av}},{ }^{\circ} \mathrm{C}$ \\
\hline 30 & 5 & 1719 & 50 & 10 & 1899 & 70 & 5 & 1849 \\
30 & 10 & 1682 & 70 & 5 & 1949 & 70 & 10 & 1838 \\
30 & 20 & 1703 & 70 & 10 & 1918 & 100 & 5 & 1937 \\
50 & 5 & 1931 & 70 & 20 & 1760 & 100 & 10 & 1923 \\
50 & 10 & 1719 & 130 & 40 & 1943 & 100 & 20 & 1804 \\
50 & 20 & 1565 & 130 & 50 & 1930 & 130 & 5 & 1986 \\
70 & 5 & 1922 & 130 & 70 & 1902 & 130 & 10 & 1962 \\
70 & 10 & 1886 & 130 & 80 & 1748 & 130 & 20 & 1929 \\
70 & 20 & 1786 & 150 & 50 & 1997 & 150 & 40 & 1877 \\
130 & 50 & 1963 & 150 & 60 & 1918 & 150 & 60 & 1850 \\
130 & 60 & 1936 & 150 & 70 & 1804 & 150 & 70 & 1842 \\
130 & 70 & 1906 & 170 & 40 & 2042 & 150 & 80 & 1857 \\
150 & 50 & 1999 & 170 & 50 & 1963 & 170 & 40 & 1933 \\
150 & 60 & 1808 & 170 & 60 & 1875 & 170 & 50 & 1899 \\
150 & 70 & 1799 & 170 & 70 & 1873 & 170 & 60 & 1904 \\
150 & 80 & 1763 & 170 & 80 & 1807 & 170 & 70 & 1873 \\
170 & 50 & 2032 & 200 & 40 & 2060 & 170 & 80 & 1917 \\
170 & 60 & 1917 & 200 & 50 & 1990 & 200 & 40 & 1949 \\
170 & 70 & 1885 & 200 & 60 & 1950 & 200 & 50 & 1928 \\
170 & 80 & 1828 & 200 & 70 & 1855 & 200 & 80 & 1939 \\
\hline
\end{tabular}

$\mathrm{NB}$ : P, W - laser beam power; $\mathrm{V}, \mathrm{mm} / \mathrm{s}$ - laser beam scanning speed; $T_{\mathrm{av}},{ }^{\circ} \mathrm{C}$ - average temperature on the surface of molten pool.

working wave lengths $\lambda$ is $0.60 \div 0.95 \mu \mathrm{m}$, an instrumental error is $\pm 0.5 \%$.

\section{Experimental results}

During the SLM-operating temperature was measured by on four different wave lengths $\lambda(0.651,0.748,0.840$, $0.927)$. The received pyrometer data were compared with the used input factors of SLM-processing. For each experiment was accounted average temperature of the molten pool surface. The received data were represented for each of laser beam mode (Tab. 2). The data were obtained only for the samples, which was formed on the appropriate way as formed 3D-objects. The samples with the defects were not taken in account.

Based on the received data, the 3D-graphs of dependence between average temperature and used SLMprocessing factors were obtained (Fig. 4). The graphs show a different picture of the dependences, which can give a wide field of the theoretical research the technological limits of SLM-processing and better understanding the nature of processing for increasing of technological productivity with extra high values of the laser power: from $200 \mathrm{~W}$, which are already available on the industrial samples of SLM-machine, to $1 \mathrm{~kW}$, which could be more desirable for future development of the technology in the frames of real industrial needs.

For each of the experiment in accordance with obtained diameter of laser beam spot on the surface of the powder and used factors of SLM-processing, the energetic
Table 3. Parameters of obtained laser beam spot on the surface of the powder for different types of laser beam power density distribution.

\begin{tabular}{cc}
\hline Type of laser beam power & Effective diameter, \\
density distribution (Mode) & $\mathrm{mm}$ \\
\hline Gaussian & 0.109 \\
Flat-top & 0.200 \\
Inverse Gaussian & 0.300 \\
\hline
\end{tabular}

contribution was accounted by next formula:

$$
E_{C}=\frac{P}{D_{E} \times V}
$$

The obtained by optical method the effective diameters $D_{E}\left(\mathrm{~J} / \mathrm{m}^{2}\right)$ of laser beam spot measured by CCD-camera LaserCam HRTM on the surface of the powder are represented in the Table 3 .

The results of the calculation of energetic contribution is represented in Table 4 . For the convenience of calculation, the all parameters in millimeters were transferred in meters.

The linear tends of the dependences between measured temperatures in the molten pool and calculated energetic contributions presented on the Figure 5. Picture shows that graphs, obtained for Inverse-Gaussian laser beam power distribution has more smoothly character and has more tendencies for improving of the energetic contribution impact into processing with the possibility to stay in the range of the SLM-processing working temperature of the molten pool with the purpose to enlarge 


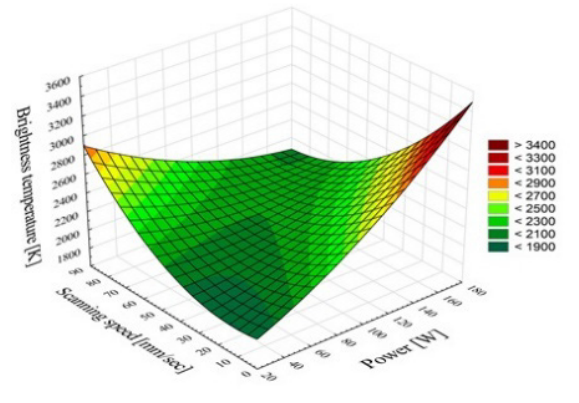

(a)

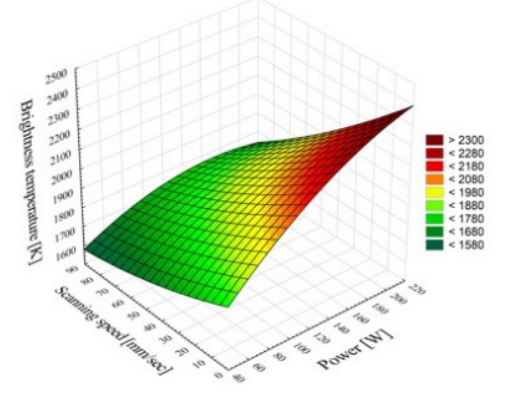

(b)

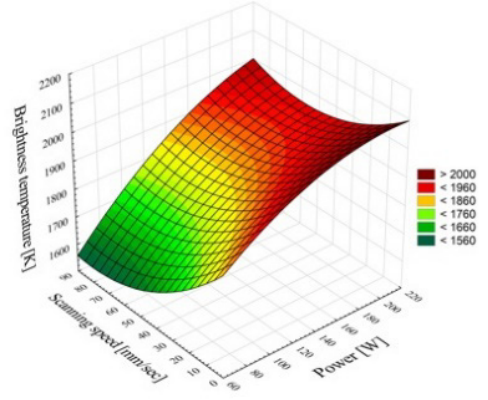

(c)

Fig. 4. 3D-graphs of dependence between average temperature and used SLM-processing factors, where: (a) for Gaussian laser beam mode, (b) for Flat-top laser beam mode and (c) for Inverse Gaussian laser beam mode.

Table 4. Calculated energetic contribution of the laser beam.

\begin{tabular}{|c|c|c|c|c|c|c|c|c|}
\hline \multicolumn{9}{|c|}{ Gaussian laser beam mode (effective dimeter $=0.109 \times{ }^{10-3} \mathrm{~m}$ ) } \\
\hline \multicolumn{9}{|c|}{$\mathrm{V}, \mathrm{m} / \mathrm{s}$} \\
\hline$\overline{\mathrm{P}, \mathrm{W}}$ & 0,005 & 0,01 & 0,02 & 0,04 & 0,05 & 0,06 & 0,07 & 0,08 \\
\hline 30 & $6, \mathrm{E}+07$ & $3, \mathrm{E}+07$ & $1, \mathrm{E}+07$ & $7, \mathrm{E}+06$ & $6, \mathrm{E}+06$ & $5, \mathrm{E}+06$ & $4, \mathrm{E}+06$ & $3, \mathrm{E}+06$ \\
\hline 50 & $9, \mathrm{E}+07$ & $5, \mathrm{E}+07$ & $2, \mathrm{E}+07$ & $1, \mathrm{E}+07$ & $9, \mathrm{E}+06$ & $8, \mathrm{E}+06$ & $7, \mathrm{E}+06$ & $6, \mathrm{E}+06$ \\
\hline 70 & $1, \mathrm{E}+08$ & $6, \mathrm{E}+07$ & $3, \mathrm{E}+07$ & $2, \mathrm{E}+07$ & $1, \mathrm{E}+07$ & $1, \mathrm{E}+07$ & $9, \mathrm{E}+06$ & $8, \mathrm{E}+06$ \\
\hline 130 & $2, \mathrm{E}+08$ & $1, \mathrm{E}+08$ & $6, \mathrm{E}+07$ & $3, \mathrm{E}+07$ & $2, \mathrm{E}+07$ & $2, \mathrm{E}+07$ & $2, \mathrm{E}+07$ & $1, \mathrm{E}+07$ \\
\hline 150 & $3, \mathrm{E}+08$ & $1, \mathrm{E}+08$ & $7, \mathrm{E}+07$ & $3, \mathrm{E}+07$ & $3, \mathrm{E}+07$ & $2, \mathrm{E}+07$ & $2, \mathrm{E}+07$ & $2, \mathrm{E}+07$ \\
\hline 170 & $3, \mathrm{E}+08$ & $2, \mathrm{E}+08$ & $8, \mathrm{E}+07$ & $4, \mathrm{E}+07$ & $3, \mathrm{E}+07$ & $3, \mathrm{E}+07$ & $2, \mathrm{E}+07$ & $2, \mathrm{E}+07$ \\
\hline \multicolumn{9}{|c|}{ Flat-top laser beam mode (effective dimeter $\left.=0.200 \times{ }^{10-3} \mathrm{~m}\right)$} \\
\hline \multicolumn{9}{|c|}{$\mathrm{V}, \mathrm{m} / \mathrm{s}$} \\
\hline $\mathrm{P}, \mathrm{W}$ & 0,005 & 0,01 & 0,02 & 0,04 & 0,05 & 0,06 & 0,07 & 0,08 \\
\hline 50 & $5, \mathrm{E}+07$ & $3, \mathrm{E}+07$ & $1, \mathrm{E}+07$ & $6, \mathrm{E}+06$ & $5, \mathrm{E}+06$ & $4, \mathrm{E}+06$ & $4, \mathrm{E}+06$ & $3, \mathrm{E}+06$ \\
\hline 70 & $7, \mathrm{E}+07$ & $4, \mathrm{E}+07$ & $2, \mathrm{E}+07$ & $9, \mathrm{E}+06$ & $7, \mathrm{E}+06$ & $6, \mathrm{E}+06$ & $5, \mathrm{E}+06$ & $4, \mathrm{E}+06$ \\
\hline 130 & $1, \mathrm{E}+08$ & $7, \mathrm{E}+07$ & $3, \mathrm{E}+07$ & $2, \mathrm{E}+07$ & $1, \mathrm{E}+07$ & $1, \mathrm{E}+07$ & $9, \mathrm{E}+06$ & $8, \mathrm{E}+06$ \\
\hline 150 & $2, \mathrm{E}+08$ & $8, \mathrm{E}+07$ & $4, \mathrm{E}+07$ & $2, \mathrm{E}+07$ & $2, \mathrm{E}+07$ & $1, \mathrm{E}+07$ & $1, \mathrm{E}+07$ & $9, \mathrm{E}+06$ \\
\hline 170 & $2, \mathrm{E}+08$ & $9, \mathrm{E}+07$ & $4, \mathrm{E}+07$ & $2, \mathrm{E}+07$ & $2, \mathrm{E}+07$ & $1, \mathrm{E}+07$ & $1, \mathrm{E}+07$ & $1, \mathrm{E}+07$ \\
\hline 173 & $2, \mathrm{E}+08$ & $9, \mathrm{E}+07$ & $4, \mathrm{E}+07$ & $2, \mathrm{E}+07$ & $2, \mathrm{E}+07$ & $1, \mathrm{E}+07$ & $1, \mathrm{E}+07$ & $1, \mathrm{E}+07$ \\
\hline \multicolumn{9}{|c|}{ Inverse Gaussian laser beam mode (effective dimeter $=0.300 \times{ }^{10-3} \mathrm{~m}$ ) } \\
\hline \multicolumn{9}{|c|}{$\mathrm{V}, \mathrm{m} / \mathrm{s}$} \\
\hline $\mathrm{P}, \mathrm{W}$ & 0,005 & 0,01 & 0,02 & 0,04 & 0,05 & 0,06 & 0,07 & 0,08 \\
\hline 70 & $5, \mathrm{E}+07$ & $2, \mathrm{E}+07$ & $1, \mathrm{E}+07$ & $6, \mathrm{E}+06$ & $5, \mathrm{E}+06$ & $4, \mathrm{E}+06$ & $3, \mathrm{E}+06$ & $3, \mathrm{E}+06$ \\
\hline 130 & $9, \mathrm{E}+07$ & $4, \mathrm{E}+07$ & $2, \mathrm{E}+07$ & $1, \mathrm{E}+07$ & $9, \mathrm{E}+06$ & $7, \mathrm{E}+06$ & $6, \mathrm{E}+06$ & $5, \mathrm{E}+06$ \\
\hline 150 & $1, \mathrm{E}+08$ & $5, \mathrm{E}+07$ & $3, \mathrm{E}+07$ & $1, \mathrm{E}+07$ & $1, \mathrm{E}+07$ & $8, \mathrm{E}+06$ & $7, \mathrm{E}+06$ & $6, \mathrm{E}+06$ \\
\hline 170 & $1, \mathrm{E}+08$ & $6, \mathrm{E}+07$ & $3, \mathrm{E}+07$ & $1, \mathrm{E}+07$ & $1, \mathrm{E}+07$ & $9, \mathrm{E}+06$ & $8, \mathrm{E}+06$ & $7, \mathrm{E}+06$ \\
\hline 173 & $1, \mathrm{E}+08$ & $6, \mathrm{E}+07$ & $3, \mathrm{E}+07$ & $1, \mathrm{E}+07$ & $1, \mathrm{E}+07$ & $1, \mathrm{E}+07$ & $8, \mathrm{E}+06$ & $7, \mathrm{E}+06$ \\
\hline
\end{tabular}

significantly the productivity of the process. Meanwhile the graphs obtained for Flat-top laser beam power density distribution has the same character as the Gaussian one on the energetic contribution level, which was proved by the described previous experiments for the formation of the single tracks as well [7]. To obtain more details for the presented data, continuation of the experimental and calculation work is needed.

In Figure 6 the results of the modeling for the research of principal perspectives and limits in productivity improvement of selective laser melting with the factors in range for scanning speed $\mathrm{V}$ from 0 up to $200 \mathrm{~mm} / \mathrm{s}$ and power $\mathrm{P}$ from 0 up to $500 \mathrm{~W}$ for each of the developed mode of laser beam. The picture was obtained by calcu- lation of the formula of temperature fields of the molten pool (formula for each mode is presented on the following graph) based on the empiric data received by the described experimental work. The picture of the temperature fields significantly shows that continuation of the research in the direction of direct linear enlargement of the laser beam power for Gaussian laser beam mode and Flat-top laser beam mode has no technological sense with the proportional linear enlargement of the scanning speed, which is obvious in this case. The principal perspectives in the improvement of the SLM-processing productivity can be achieved by use of Inverse-Gaussian laser beam mode in the next meanings: laser beam power from 130 up to $500 \mathrm{~W}$; laser beam scanning speed from $60-80 \mathrm{~mm} / \mathrm{s}$ up 


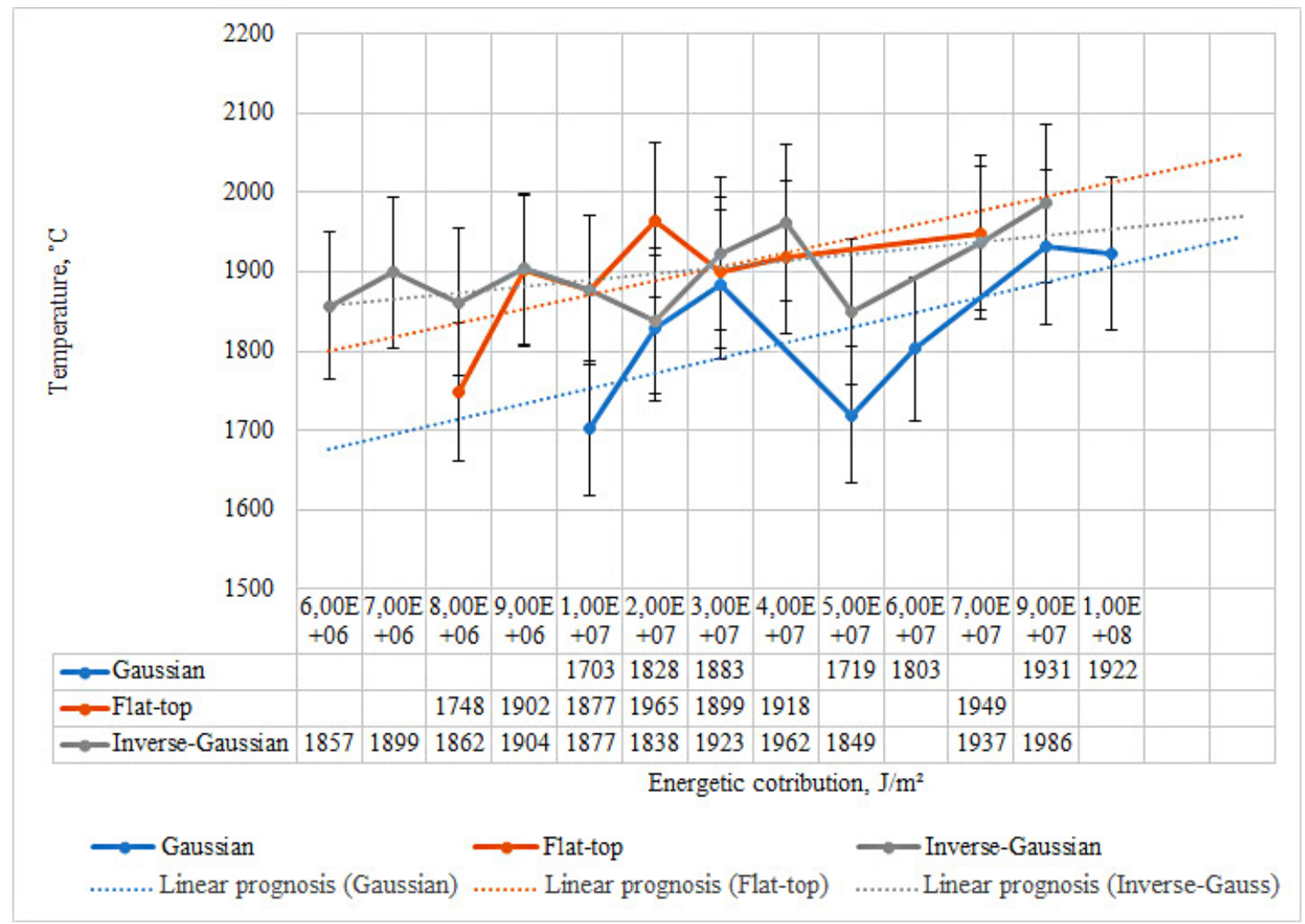

Fig. 5. Tendencies and linear prognosis of the possible increase of the SLM-processing productivity with the evaluation of the energetic contribution for different laser beam power density distributions.

to $140-160 \mathrm{~mm} / \mathrm{s}$ for Co-Cr powder. The range of working temperature of the molten pool was defined from 1680 up to $2060{ }^{\circ} \mathrm{C}$. More interest in the context of the described objective in the current work has an area of the technological gap in the frames of the power from 450 to $500 \mathrm{~W}$ and scanning speed from 130 to $160 \mathrm{~mm} / \mathrm{s}$.

\section{Conclusions}

On the developed experimental setup, the temperature data for different laser beam power density distribution were obtained by pyrometer. The data were compared with the used SLM-processing factors as laser beam power and laser beam scanning speed. Based on it, the $3 \mathrm{D}$-graphs of the dependences between average means of measured temperatures and used factors were modeled. The tendencies of Inverse Gaussian laser beam power density distribution has a potential for the purpose of the work to enlarge significantly the productivity of SLMprocessing with the rise of the laser beam power and with the rise of laser beam scanning speed. In this case, the temperature of the molten pool could stay in the limits of the range of working temperatures (from 1680 to $2060{ }^{\circ} \mathrm{C}$ ). Otherwise the energetic contribution into the SLM-processing can be too much low (not enough for starting of melting processes) or too much high, which leads to formation of the plasma cloud and active evaporation of the material from the surface of molten pool, including possible sublimation (direct evaporation of the material without liquid phase formation).

For the used range of the SLM-processing factors, the energetic contribution was calculated for each group of the experiments. The obtained calculated data was compared with the measured temperature. The modeling of the linear prognosis for each laser beam power density distribution confirmed that Invense Gaussian laser beam mode has a huge potential for the increase of SLM-processing productivity. For further modeling of the behavior the tendencies of the dependences between laser beam energetic distribution and measured working temperatures in the molten pool, it is necessary to continue the experiments on the developed experimental setup.

The future perspectives of the improvement of the productivity for SLM-processing can be in the direction of the enlargement of the laser beam power from $500 \mathrm{~W}$ up to $1 \mathrm{~kW}$; meanwhile the enlargement of the scanning speed should be in the range from $130 \mathrm{~mm} / \mathrm{s}$ up to $200 \mathrm{~mm} / \mathrm{s}$. For the evaluation of these perspectives needs more data to precise the formulas for the modeling.

Acknowledgements. This work has been financed by the Ministry of Education and Science of the Russian Federation in the frame of governmental task in the field of scientific activities (task order No. 9.811.2014/K).

The work is carried out on the equipment of the Center of collective use of MSTU "STANKIN". 
V.D. Gurin et al.: Mechanics \& Industry 17, 714 (2016)

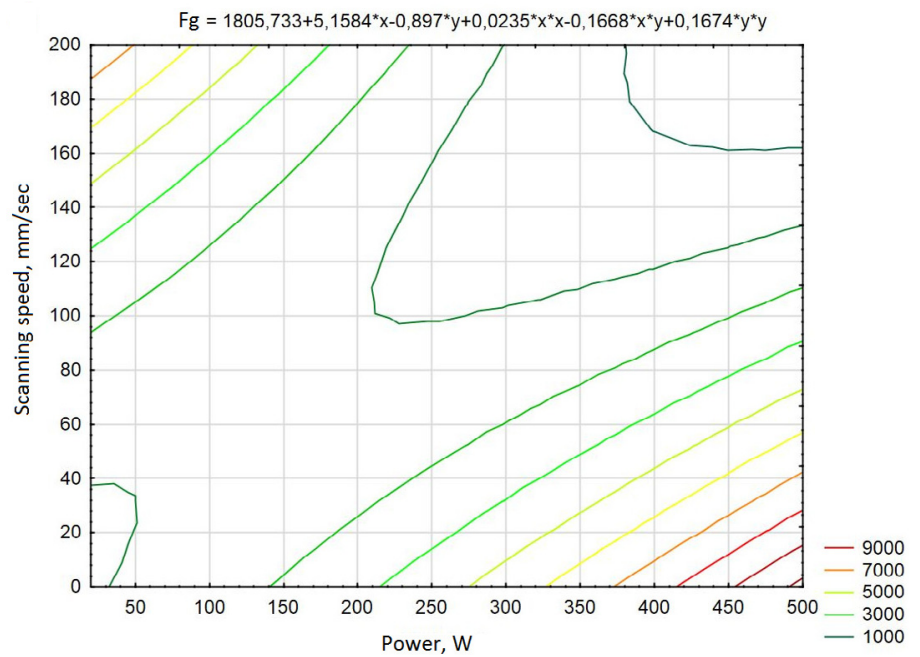

(a)

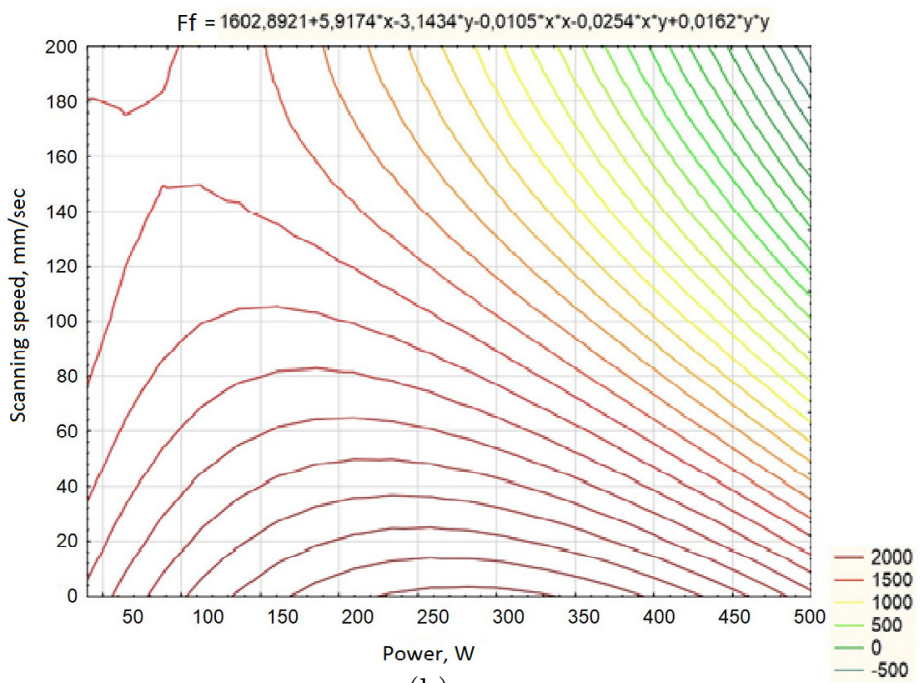

(b)

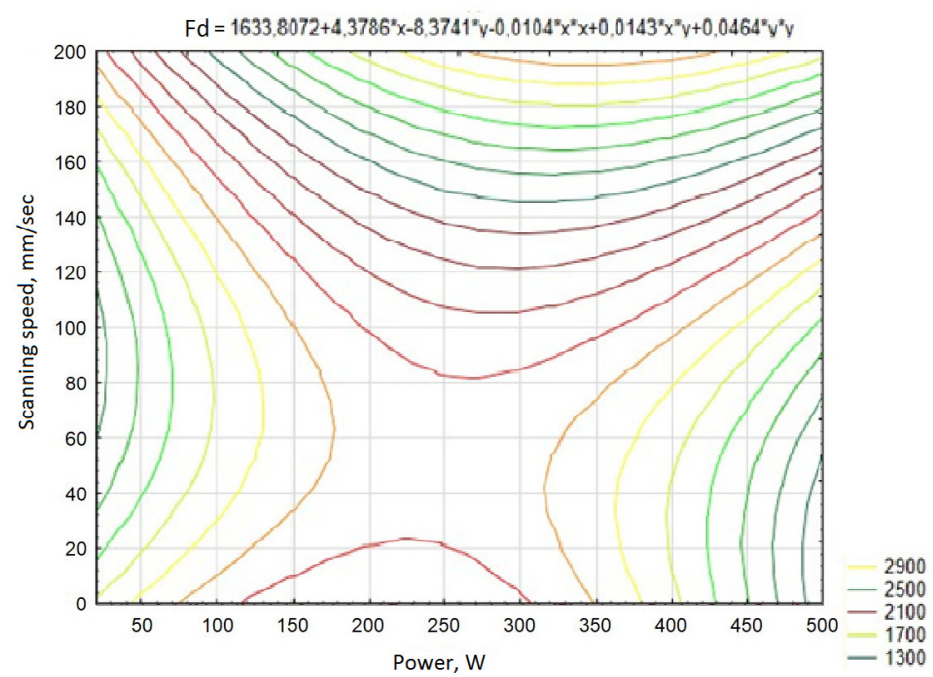

(c)

Fig. 6. Results of the modeling for the research of principal perspectives and limits in productivity improvement of selective laser melting with the factors in range for scanning speed V up to $200 \mathrm{~mm} / \mathrm{s}$ and power P up to $500 \mathrm{~W}$ : (a) for Gaussian mode; (b) for Flat-top mode; (c) for Inverse-Gaussian mode. 


\section{References}

[1] T. Wohlers, Wohlers Report 2016: 3D Printing and Additive Manufacturing State of the Industry - Annual Worldwide Progress Report, Wohlers Associates, Inc, Fort Collins, Colarado, 2016

[2] S.N. Grigoriev, V.I. Teleshevskii, Measurement problems in technological shaping processes, Measurement Techniques 54 (2011) 744-749

[3] W.E. King, A.T. Anderson, R.M. Ferencz, N.E. Hodge, C. Kamath, S.A. Khairallah, A.M. Rubenchik, Laser powder bed fusion additive manufacturing of metals; physics, computational, and materials challenges, Appl. Physics Rev. 2 (2015) 041304

[4] S.A. Khairallah, A.T. Anderson, A. Rubenchik, W.E. King, Laser powder-bed fusion additive manufacturing: Physics of complex melt flow and formation mechanisms of pores, spatter, and denudation zones, Acta Materialia 108 (2016) 36-45

[5] D. Gua, H. Wanga, F. Changa, D. Daia, P. Yuana, Y.-C. Hagedornc, W. Meiners, Selective Laser Melting Additive Manufacturing of TiC/AlSi10Mg Bulk-form Nanocomposites with Tailored Microstructures and Properties, Physics Procedia 56 (2014) 108-116

[6] M. Merklein, R. Plettke, D. Junker, A. Schaub, B. Ahuja, Mechanical Testing of Additive Manufactured Metal Parts, Key Engineering Materials 651-653 (2015) $713-718$

[7] I.V. Zhirnov, P.A. Podrabinnik, A.A. Okunkova, A.V. Gusarov, Laser beam profiling: experimental study of its influence on single-track formation by selective laser melting, Mechanics \& Industry 16 (2015) 709

[8] A. Okunkova, P. Peretyagin, Yu. Vladimirov, M. Volosova, R. Torrecillas, S.V. Fedorov, Laser-beam modulation to improve efficiency of selecting laser melting for metal powders, Proc. SPIE 9135 Laser Sources and Applications II (May 1, 2014) 913524

[9] A. Okunkova, M. Volosova, P. Peretyagin, Yu. Vladimirov, I. Zhirnov, A.V. Gusarov, Experimental approbation of selective laser melting powders by usage of non-Gaussian power density distribution, Phys. Proc. 56 (2014) 48-57

[10] I. Yadroitsev, A. Gusarov, I. Yadroitsava, I. Smurov, Single track formation in selective laser melting of metal powders, J. Mater. Process. Technol. 210 (2010) 16241631
[11] I. Yadroitsev, P. Bertrand, G. Antonenkova, S. Grigoriev, I. Smurov, Use of track/layer morphology to develop functional parts by selective laser melting, J. Laser Appl. 5 (2013) 052003

[12] D. Kotoban, S. Grigoriev, I. Shishkovsky, Study of 3D laser cladding for Ni85Al15 superalloy, Phys. Proc. 56 (2014) 262-268

[13] T.V. Tarasova, Prospects of the use of laser radiation for raising the wear resistance of corrosion-resistant steels, Metal Sci. Heat Treatment 52 (2010) 284-288

[14] P.W. Rhodes, D.L. Shealy, Refractive optical systems for irradiance redistribution of collimated radiation: their design and analysis, Appl. Opt. 19 (1980) 3545-3553

[15] C.Y. Han, Y. Ishii, K. Murata, Reshaping collimated laser beams with Gaussian profile to uniform profiles, Appl. Opt. 22 (1983) 3644-3647

[16] C. Wang, D.L. Shealy, Design of gradient-index lens systems for laser beam reshaping, Appl. Opt. 32 (1993) 4763-4769

[17] K. Nemoto, T. Fujii, N. Goto, T. Nayuki, Transformation of a laser beam intensity profile by a deformable mirror, Opt. Lett. 21 (1996) 168-170

[18] J. Jia, C. Zhou, X. Sun, L. Liu, Superresolution laser beam shaping, Appl. Opt. 43 (2004) 2112-2117

[19] A. Hendriks, D. Naidoo, F.S. Roux, C. López-Mariscal, A. Forbes, The generation of flat-top beams by complex amplitude modulation with a phase-only spatial light modulator, Proc. SPIE 8490, Laser Beam Shaping XIII, 849006 (October 15, 2012)

[20] F.M. Dickey, S.C. Holswade, D.L. Sheal, Laser Beam Shaping Application, Taylor and Francis Group, CRC Press, 2006

[21] R. Voelkel, K.J. Weible, Laser Beam Homogenizing: Limitations and Constraints, Proc. SPIE 7102, Optical Fabrication, Testing, and Metrology III, 71020J (September 25, 2008)

[22] H. Ma, Z. Liu, P. Zhou, X. Wang, Y. Ma, X. Xu, Generation of flat-top beam with phase-only liquid crystal spatial light modulators, J. Opt. 12 (2010) 045704

[23] R. Bourouis, K. Ait Ameur, H. Ladjouze, Optimization of the Gaussian beam flattening using a phaseplate, J. Mod. Opt. 44 (1997) 1417-1427

[24] D.L. Shealy, J.A. Hoffnagle, Laser beam shaping profiles and propagation, Appl. Opt. 45 (2006) 5118-5131 